\title{
Momentum meets value investing in a small European market
}

\author{
Júlio Lobão $^{1}$ (iD \& Marcos Azeredo ${ }^{1}$
}

\begin{abstract}
In this paper, we investigate two prominent market anomalies documented in the finance literature - the momentum effect and value-growth effect. We conduct an outof-sample test to the link between these two anomalies recurring to a sample of Portuguese stocks during the period 1988-2015. We find that the momentum of value and growth stocks is significantly different: growth stocks exhibit a much larger momentum than value stocks. A combined value and momentum strategy can generate statistically significant excess annual returns of $10.8 \%$. These findings persist across several holding periods up to a year. Moreover, we show that macroeconomic variables fail to explain value and momentum of individual and combined returns. Collectively, our results contradict market efficiency at the weak form and pose a challenge to existing asset pricing theories.
\end{abstract}

Keywords Value-growth effect $\cdot$ Momentum effect $\cdot$ Macroeconomic factors $\cdot$ Stock market $\cdot$ Portugal

JEL Codes: $\mathrm{G} 11 \cdot \mathrm{G} 12 \cdot \mathrm{G} 14 \cdot \mathrm{G} 15$

The original version of this article was revised: The article title is now corrected.

Júlio Lobão

jlobao@fep.up.pt

Marcos Azeredo

marcos.c.azeredo@gmail.com

1 School of Economics and Management, University of Porto, Rua Dr. Roberto Frias, 4200-464 Porto, Portugal 